\title{
Empowering Social Science Research in the Big-Data Era: Addressing Quantyphobia in IR Researches ${ }^{1}$
}

\author{
Farizal Mohd Razalli ${ }^{2}$
}

\begin{abstract}
This paper tries to explore the employment of quantitative approach in political researches focusing on international relations (IR) or international politics. A debate emerged in the 90 s on whether IR or the field of international politics should be driven by quantitative (positivistic) approach at the expense of qualitative (interpretivist) approach. The debate then expanded to explicitly argue for an increased use of formal methods that are mathematically-based to study IR phenomena. It triggered then a quick reaction from hardcore IR specialists who warned against mathematizing IR for fear of turning the field into a mechanical field that crunches numbers. Such a fear is further substantiated by the observation that many quantitative works in IR have moved farther away from developing theory to testing hypotheses. Some scholars have even suggested that it is epistemologically realism vs. instrumentalism; something that is unsurprising given the dominance of realism in IR for many years. This paper does not suggest that heavy emphasis on qualitative approach leads to a inferior research output. However, it does suggest an transformative incapability among IR scholars to accommodate to contemporary global changes. The big-data analytics have affected the intellectual community of late with the influx of data. These data are both qualitative and quantitative. Nonetheless, analyzing them requires one to be familiar with quantitative methods lest one risks not being able to offer a research outcome that is not only sound in its argumentation but also robust in its analytical logic. Furthermore, with so much data on the social media, it is almost unthinkable for meaningful interpretation to be made without even the simplest descriptive statistical methods. The key findings reveal that in ensuring its relevance, international political researches have to start adapting to the contemporary changes by building new capability apart from upscaling existing capacity.
\end{abstract}

Keywords: Qualitative, Quantitative, Quantyphobia, Big-Data Analytics, IR Methodology, Social Science Research

\footnotetext{
${ }^{1}$ Key ideas in this paper were presented during the International Symposium on Social Science in the Age of Transformation and Disruption: Its Relevance, Role, and Challenge (SOSS) 2018, Universitas Gadjah Mada, Yogyakarta, Indonesia, September 4-5, 2018. The author wishes to thank the international panelists for their constructive comments during the presentation.

${ }^{2}$ Universiti Kebangsaan Malaysia (UKM).Corresponding e-mail: farizal@ukm.edu.my.
} 


\section{Introduction}

"In academic [qualitative] research, you cannot forecast things [research phenomena] but [you] must explain [analytically describe] things". It is a typical commentary heard among IR-political science academics, at least in Malaysia, when assessing academic works that attempt at employing advanced quantitative approach e.g., regression analysis. The author makes the following two conclusions from such a commentary.

Firstly, many IR-political scientists still remain skeptical about the contemporary global changes that they are supposed to deal with in their day-to-day work routine (Wayman \& Diehl, 1994; Mearsheimer, 1994; Schweller, 1997). The realist paradigm that recognizes change as the only constant in the contemporary system is still strongly dominating the field especially international politics ${ }^{3}$ (see more interesting IR works that talk about change in the international system like Gilpin, 1981; Wendt, 2015; Korab-Karpowicz, 2017). Rather than trying to analyze change, one is better off analyzing causes and effects of the change (Carr, 1946). Secondly, forecasting is regarded as a risky activity to uncovering reasons behind a research phenomenon (see Kristóf, 2006) . There is always the question of how reliable one's data are or whether or not one has sufficient and the relevant data to forecast. As a result, one is better off keeping his analysis to confirmed data. Often, these confirmed data refer to post-phenomenon data namely reports, interview transcripts with subjects involved and expert opinions or views formed post-phenomenon.

The aforementioned conclusions share a common denominatorcertainty. It appears that IR-political scientists value highly certainty in their research work. When posed with uncertain features, be they methodologically or analytically, their level of skepticism rises and such rising skepticism explains their refusal to employ sophisticated quantitative

${ }^{3}$ In this article, international politics is used interchangeably with international relations to refer to the same meaning. 
methods or approaches in their researches. Such a hypothetical statement forms an important point in this paper. This paper does not suggest that the current emphasis on qualitative approach in international political researches, in Malaysia and in the region, yields inferior research outcomes. Rather, it tries to understand the underlying reason why qualitative approach is more preferred to its quantitative approach. This research objective distinguishes the paper from the debate between realists and instrumentalists whose aim skews toward arguing for one another's superiority in international political research.

Given the above objective, the paper is organized in the following manner. The next section briefly surveys the current state of the literature on methods and approaches in the field of international politics. It revisits some early debates on prevailing methods together with analytical arguments for and against them. The section brings in brief discussion on attitudes of IR-political science scholars, especially in Malaysia and generally in the Southeast Asian region, toward quantitive methods and assessment of how sustainable such attitudes are moving forward. The following section introduces a simple game theoretical model that represents the current quantyphobia reality among the qualitative IR scholarship. It will explicate some of the fundamental assumptions and perimeters governing the analytical model. Readers are guided through simple step-by-step explanation on the model presented. Next is the discussion of the outcome of the analysis. Key points are highlighted and further elaborated. This elaboration provides readers with better grasp of the entire discussion of the topic. Finally, the conclusion section proposes a paradigm-shift model to address the quantyphobia phenomenon among the qualitative IR scholarship particularly in Malaysia and the immediate region.

\section{Literature Review}

To be fair, IR field is no short of sound empirical works. Names like Karl W. Deutsch (1966), John Vasquez (1987), Bruce Bueno de 
Mesquita (2010) and James Fearon (1995) to name a few have done excellent empirical analyses on IR phenomena. These works range from hypothesis testing to inferential statistical analyses to complex mathematical modelling. In fact, over the last decades, the field has seen influx of quantitative works done as evidenced by the number of journal articles published in some of the field's leading journals. Nonetheless, this phenomenon is not common across the globe. The United States of America has singly seen a dramatic rise in IR quantitative works. On the contrary, the other world's regions has been lagged behind with some regions experiencing a complete absence of quantitative works in IR.

Such phenomenon outside the United States of America is however understandable. The IR intellectual discourse has been strongly dominated by American tradition (Krippendorff, 1987). IR as a field was practically nurtured on the American soil with its prominence parallelly tracks the rise of the American hegemony as a global superpower. As the U.S. government found itself engaged in myriad foreign policy tasks across the globe, the demand for data-driven policy analysis grew significantly. Merritt (1985) attributed the growth of quantitative research in America to the progress in technology. The technological advancement then had equally advanced scientific analysis in at least three ways: the availability of databases; the methodologies for analyzing data; and the high speed electronic computers to enable the treatment of complex data (in today's term this is equivalent to the big data).

The mushrooming of quantitative works in IR especially in the late 1970s coincided with the increasing criticism against IR's predominant paradigm- Realism. Many of the realist grand propositions like balance of power, occurrence of war and peace, and alliances came under huge intellectual scrutiny. Miller (1978) provided a much broader understanding of international systems. His living systems examine attributes and interaction patterns across seven levels from the cell through the nation-state to global society. Miller's work could have well 
been inspired by much earlier works on systems and actors namely that of Harold Lasswell and Abraham Kaplan (1950), and Morton Kaplan (1957).

The former contends that individuals [who make up the nationstate system) are multivalent in that they pursue variety of goals namely power, wealth, enlightenment, well-being, skill, affection, rectitude and respect. These individuals vary from person to person in terms of the priority of these goals. By extension then nation-states as actors in the international system also pursue multivalent policies with different weightings. While some may be preoccupied with amassing power over others, others may be more concerned with improving domestic economy, enhancing their respective technological development or propagating a particular moral or ethical code.

The latter, on the other hand, having observed the variability patterns of interaction across systems, sees the possibility of alternative [other than the one offered by the realist paradigm] structuring of the international system. The Western world once enjoyed both balance-ofpower and bipolar arrangement; hence it is plausible to imagine other arrangement types like pure hierarchy or unit-veto systems. And for better or worse, these insights from a system analysis of international politics have expanded the conceptualization of international political processes. Even hard-core realist scholars like Robert Keohane (1984) through his work, Theory of World Politics: Structural Realism and Beyond, modifies the traditional realist paradigm to incorporate the recognition that systemic structure (rather than domestic polities) imposes constraints on actors' behavior or better known as structural Realism.

Realism is not the only approach being criticized. Its counterpart Liberalism is also under close scrutiny by the growing quantitative fraternity. The idea of peace as being advanced by the liberal camp has triggered some fundamental quantitative works to confirm some of the appealing yet controversial hypotheses. The democratic peace 
argument, in this case, is one case in point. This article however is concerned with the developments that made such quantitative works possible.

The data development has flourished since the late 1960s. The Yale Data program, that assembled data on 75 variables for 133 states, facilitated quantitative works like that of Arthur Banks and Robert Textor (1983) on cross-polity survey. The New York Times and Keesing's Archive, which serves as databases on the occurrence of both domestic and international events like coup d'état, riots, regime change, armed interventions and wars, have facilitated the quantitative examination of events nation states participated in. Of more robust database development of all times is the Correlates of War project that was founded by J. David Singer at the University of Michigan in 1964. This database rigorously categorizes every international war since 1816. Not only has the database served as an excellent source for quantitative works on understanding wars (e.g., Geller and Singer, 1998), it has also facilitated more pioneering paradigmatic works like Color It Morgenthau thesis by John A. Vasquez et. al (1973) that attempts at advocating paradigm change in IR. ${ }^{4}$

The quantitative vs. qualitative debate in IR is incomplete without bringing in the discussion on methodology. In fact all of the aforementioned quantitative works (as well as the following ones) use one or a combination of quantitative methods to arrive at their findings. Generally, quantitative methods employed in the IR field are divided into two main categories namely statistical and mathematical models. The statistical category can be further divided into descriptive and inferential methods. These methods employ arithmetic central tendency

\footnotetext{
${ }^{4}$ This work has attracted many criticisms of which beyond the scope of this present article. What is worth noting, however, some of these critiques also employ equally extensive quantitative approach in their counter-article, which cements further quantitative methodology's position in the field. See for example William B. Moul, (1982), Colouring by Numbers: Comments on a Quantitative Study of Quantitative Studies of International Politics, Review of International Studies, 8:2, 129-133.
} 
measures (see works by Muhammet A. Bas, 2012; Brian Rathbun, 2012; Peter D. Hoff \& Michael D. Ward, 2004) as well as forecasting tools like regression analysis to explain causal-effect relationships (see works by Peter M. Aronow \& Cyrus Samii, 2016; Gary King \& Langche Zeng, 2001).

Meanwhile, the mathematical models include formal modelling of IR phenomena using mathematics. Mathematical models are often abstract and force researchers to be precise in the use of language and logic. These models consist of equations which can get very complex that people who are not cognoscenti may find them scary (see for example one of the classics in mathematical modelling on arms races by Lewis Frye Richardson, 1960). The game-theoretic models range from simple one-level game-theoretic models that either represent one-off encounter (see Joanne Gowa \& Edward D. Mansfield, 1993; David R. Mares, 1988) or repeated encounters (see for example Pierpaolo Battigalli, 1997; David M. Kreps \& Robert Wilson, 1982) to more complex two- or multilevel game-theoretic models (see for example Robert Putnam, 1988).

Still, there exists other modelling techniques like the Kolmogorov's model of stochastic processes (see for example Peter J. Hammond, 2007), ecological modelling (see for example Ian Bellany, 1999) and computer-algorithmic models (see discussions on formal computerbased models in Peter G. Bennett, 1991; Michael Nicholson, 1989). The computer-algorithmic models leverage upon the high speed and efficient modern computers to deal with more complex real-world IR phenomena modelling.

There is no denying that quantitative IR flourishes in America. Other regions like Southeast Asia clearly lags behind in producing quantitative works on IR. This can be verified by a quick survey on authors of those quantitative works who are by majority of American (with some European) institutions. To put things into perspective, there are equally small number of authors from, say, Asian institutions even when one takes into account collaborative authorship. 
In recent years, Southeast Asian IR scholarship does appear in a handful of leading IR journals. Nonetheless, almost $70-80 \%$ of these works are qualitative in nature (see for example Ngeow Chow Bing, 2017) with the remaining 20-30\% are problematically fused in nature (see for example Ravichandran Moorthy \& Guido Benny, 2012). Mainly works on international political economy employ a mixture of statistical and qualitative content analysis (see for example Jaechun Kim \& Pablo Andres Ramirez, 2014).

In view of the American context discussed above, the strong preference for qualitative approach should worth an investigation. Several hypotheses can be posited: 1) the pool of IR indigenous scholars in the region is small hence a relatively small portion or a total absence of quantitative works is expected; 2) most of these indigenous IR scholars are trained in qualitative approach hence they are more capable in qualitative rather than quantitative research (see Onwuegbuzie \& Leech, 2005; Tobi \& Kampen, 2017); and 3) there exists systemic fear for quantitative research as it requires highly numerical skill and mathematical logic, often thought as unlearnable. This article is more interested in the third hypothesis.

It is the fear for quantitative approach hence the application of its methods that requires further investigation. Justin Buchler (2009) admits that many political science students [in the U.S.A) struggle in quantitative methods courses. There seems to be a stigma that qualitative approach is the mantra framework to best study IR phenomena, regardless of the particular research questions at hand.

In one of Malaysia's leading IR departments, for instance, there are only countable theses that employ quantitative approach. Almost all new postgraduate recruits will make qualitative approach as their preferred choice for addressing their research problem regardless of its feasibility. This has led to a methodology abuse where the choice of methods is a function of personal preference rather than objective functionality. It is not surprising then to see how some of these theses 
overstretch the limits and functions of certain (qualitative) methods in order to prove their arguments.

Such exercise is dangerous as it dilutes the values of academic research that rest upon sound scientific logic and integrity. Also worrying is when these claimed qualitative theses do not even adhere to strict methodological standards of good qualitative research. Never mind the no-preference for quantitative approach, the strong preference for qualitative does not augur well for more superior research outcome. Mearsheimer and Walt (2013), when raising their concern on the theory neglect in IR research [an omen of inferior research outcome], recognize that it is not only the tragedy in quantitative IR but equally in qualitative IR scholarship.

It all boils down to one fact; that while a researcher may have his own methodological preference, it is imperative for him to be cognizant of all the other methodological options. ${ }^{5}$ Nonetheless, given the influx of data today compared to before, this article sees it crucial for researchers to be fluent in both qualitative and quantitative methodology. Appropriate strategies will be required to achieve this and the following section devotes itself toward this end. Qualitative IR scholarship must increase its strategic intellectual interaction with quantitative IR scholarship. Failing this, IR as a field will quickly find itself unsustainable hence risk itself being irrelevant in explaining the ever increasing complexities in world affairs.

\section{Game-Theoretic Model: Explaining The Status Quo}

This article develops a game-theoretic model on the interaction between the qualitative and the quantitative scholarship. For reasons of parsimony, suffice to say such choice is more illustrative than conclusive

\footnotetext{
${ }^{5}$ It should be noted though that interdisciplinary and collaborative research in other fields in the social sciences have advanced more significantly, albeit challenging, as evidenced in the works on grounding research methodology in Southeast Asian studies by (Huotari, Rüland \& Schlehe, 2014; works on methodology in interdisciplinacy research by Tobi \& Kampen, 2017).
} 
in supporting the main objective of this article to demonstrate the argument for change in the current status quo. The present article acknowledges the shortcomings resulting from such choice; nonetheless this does not in significant manner (the article believes) affect the overall generality of the argument posited in the article. The following gametheoretic model does not count itself as an application of game theory in modelling international political phenomena. Nor does it represent an application of game theory in research methodology. What it does is to try to represent the current state of affairs in a particular academic fraternity [Malaysian IR scholarship in particular] whose domineering paradigm has long been qualitative [descriptive].

The model assumes a likely interaction between the qualitative scholarship and the academic universe. For reasons of practicality, the model further assumes the qualitative scholarship is interacting with the quantitative scholarship. While the membership of the former has been clearly defined, the membership of the latter represents not necessarily the IR fraternity. The field of IR has always been interdisciplinary in nature with many of its theoretical and empirical works cut across various disciplines namely sociology, mathematics, economics, engineering, information technology, and environmental studies. Thus it is plausible to believe that in ensuring its own relevancy and long-term survival, the most sustainable way is to reach out to partners [scholars] outside the field. This partnership endeavor will trigger reactions from these external partners. This present model shows that these reactions can be diverse, which in turn result in further diverse (counter)-reactions that culminate into different outcomes. This reaction chain and outcomes give the interaction between the qualitative and the quantitative scholarship its strategic notion. ${ }^{6}$

In game theory, games or game theoretic models can either be static or dynamic. The former refers to games in which players (actors)

${ }^{6}$ Fischer et al., 2011, confirmed social science-natural science collaboration, for instance, is indeed a challenge. 
move simultaneously and independently that is without knowing the move of the other player. The latter, on the other hand, refers to games where players take turns in making their move; move upon knowing the choice of moves made by the other players. The game-theoretic model proposed in this article represents this latter category. It is also essential to identify the game-theoretic model with the information type. A game of complete information means players know all his (as well as the players') actions, strategies, outcomes and preference over these outcomes throughout the game. This also holds true vice versa. Also of importance, all players know that this a common knowledge to each and every player.

Meanwhile, a game of incomplete information is one in which players have some idea about the actions, strategies, and outcomes of the other players. However, players do not know about the other players' preferences over these outcomes. In other words, while the payoffs (outcomes) resulted from the actions (and strategies) taken are common knowledge to players, the payoff function (preference) of each players are not known. Thus, games of incomplete information refer to games with unknown types of players.

All the above assumptions effectively make all players in the game to be intelligent. And being intelligent has implication on another key feature of the game theory- rationality. The rationality principle assures that players will only choose the best move [action] that yields the best outcome. Best outcome in this case refers to the best payoff defined either in terms of material (e.g., profits) or non-material (e.g., satisfaction or pleasure). And this knowledge on rationality is available to all players.

The present model assumes the game between the qualitative and the quantitative scholarship to be a dynamic game of complete information. And because this game does not involve random act of movement by players throughout the game, it is also a perfect 
information game. It is imperative then at this point to develop both players' utility function or preference over outcome. The model identifies three factors that are key to defining both players' utility function. They are survival, epistemology and cost. Survival is the most critical factor for both players but especially for the qualitative scholarship. As the academic world is changing dramatically as a result of the big-data phenomenon, qualitative scholarship is under huge pressure to maintain its survival. Doing things under the business-asusual scenario will no longer work. Qualitative scholars have no choice but to upscale themselves or in some extreme cases convert themselves into hybrid scholars who demonstrate high eloquence and competence for both qualitative and quantitative approach. Analogizing this to language learning, these scholars are considered highly bilingual- one who masters two languages equally well that switching between the two codes is flawless.

Second factor is epistemology. Both qualitative and quantitative scholarship strive to defend its respective mode of knowledge inquiry. It is the core of their identity- one that defines their respective existence and distinguishes their respective traditions in producing knowledge. ${ }^{7}$ Both the qualitative and the quantitative scholarship will attach a sentimental value to the epistemology factor hence it is a factor for which both players will have little incentive to trade off.

Third factor concerns the cost. Here cost is defined as a composite factor that aggregates different outlays involved as a result of maintaining survival and keeping epistemology intact. When a qualitative scholar embarks on his decision to upskill himself with the new quantitative methods, there are costs involved namely the time, the effort and possibly the monetary expenditures in order to acquire the new skills. As a result, cost is the only variable that can vary indefinitely in the model.

\footnotetext{
${ }^{7}$ Such defensive attitude over one another's methodological traditions is also prevalent between area specialists and social scientists, see Huotari, 2014, p. 2.
} 
The model assumes the cost factor to be uniquely assigned to the qualitative scholarship given the fact that 1 ) the need for change is dawn upon the qualitative scholarship more than the quantitative scholarship; 2) should there be a need to undertake upskilling, such endeavor is to be pursued by qualitative scholars independently without quantitative scholars' direct sponsorship.

The utility functions of the two players are given below:

$$
\begin{aligned}
& \mathrm{U}_{\text {qualy }}=\mathrm{S}+\mathrm{D}+\mathrm{E} e^{x}-\mathrm{C} \\
& \mathrm{U}_{\text {quanty }}=\mathrm{S}+\mathrm{D}+\mathrm{E} e^{x}
\end{aligned}
$$

where S: survival

$$
\begin{aligned}
& \text { D: extinct } \\
& \text { E: epistemology } \\
& \text { C: cost }
\end{aligned}
$$

One's survival is a function of probability $(\Omega)$. Nobody can be of $100 \%$ sure that he will survive, be it in life, competition, conflict or war, or a simple task like exam (where survival is equal to passing the exam). Hence, each player's survival occurs with certain possibility that ranges between 0 and 1 . In this model, the probability value interacts directly with the epistemology factor. For all $\Omega=0$, the epistemology is assumed to be completely non-existent or $\mathrm{E}=0$. When $\Omega>0$, the epistemology will assume the value of $1, E=1$. The Euler constant suggests the compounding effect whereby a positive probability of survival will boost the sentimental value exponentially.

Hence, by incorporating the probability into the existing equations, one derives:

$$
\begin{aligned}
& \mathrm{U}_{\text {qualy }}=\mathrm{S}(\Omega)+\mathrm{D}(1-\Omega)+\mathrm{E} e^{x}-\mathrm{C} \\
& \mathrm{U}_{\text {quanty }}=\mathrm{S}(\Omega)+\mathrm{D}(1-\Omega)+\mathrm{E} e^{x} \ldots \ldots
\end{aligned}
$$

By simplifying (3) and (4) and arranging the terms, one derives the following:

$$
\begin{aligned}
& \mathrm{U}_{\text {qualy }}=\mathrm{D}+(\mathrm{S}-\mathrm{D}) \Omega+\mathrm{E} e^{x}-\mathrm{C} \\
& \mathrm{U}_{\text {quanty }}=\mathrm{D}+(\mathrm{S}-\mathrm{D}) \Omega+\mathrm{E} e^{x} \ldots \ldots
\end{aligned}
$$


The extensive form of the game is given in figure 1 below:

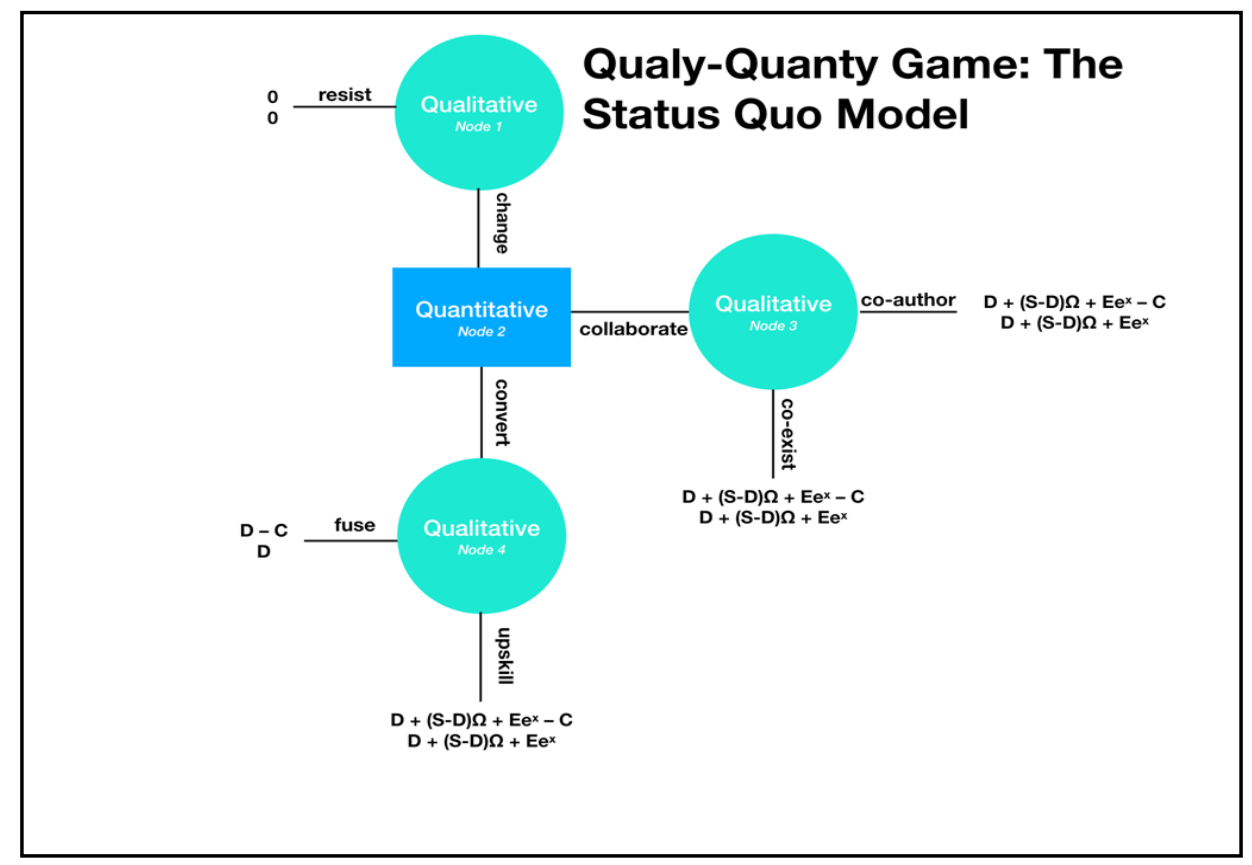

Figure 1. The status quo model

(source: Author's compilation)

The game begins with the qualitative making his ${ }^{8}$ first move at node 1 . The choice of actions available are change and resist. At node 2 , it is the quantitative's turn to make her move. She will have two choices of actions: collaborate and convert. The game continues with the qualitative making his move at either node 3 or node 4 . At both the nodes, the qualitative have two choices of actions respectively. At node 3 he can opt between co-author and co-exist. Meanwhile at node 4, he can opt for either upskill or fuse. The game ends with the qualitative deciding his course of actions. At this point, each of the players' final payoffs are given where the first row represents the qualitative's final payoff and the second row represents the quantitative's final payoff.

\footnotetext{
${ }^{8}$ The use of the male and female third person singular pronoun is to distinguish between player 1 and player 2 . This practice is common in the game theory literature. See Steven Tadelis (2013).
} 


\section{Analysis And Outcome of The Game-Theoretic Model}

The game's basic assumption is that the qualitative scholarship is strongly inclined to change the status quo. This assumption is important lest the game will not take place. Resistance (resist) will result in the maintenance of the status quo. The quantitative scholarship, upon learning the desire for change on the part of the qualitative scholarship, decide to choose collaborate. The reason for this lies in the past decision of player 1 [qualitative scholarship] at node $1 .{ }^{9}$ Sharing the same rationality, player 2 [quantitative scholarship] believes that player 1 could have resisted from the very beginning should he [player 1] believe that player 2 is going to choose convert at node 2 . In similar vein, being rational, player 1 believes that it is also not in the best interest of player 2 to choose collaborate rather than convert at node 2 given the more profitable payoffs from choosing collaborate.

Given collaborate is the best action at node 2 , it is plausible to assume that player 1 rationally believes that player 2 is expecting the highest payoff at node 3 . The concept of completeness ${ }^{10}$ induces player 1 to be confident that one of the actions between co-author and co-exist must yield the highest payoff for player 2 . To simplify things at this point (co-author and co-exist will be further defined later in this section) we assume player 2 to put higher preference for co-author than for co-exist. Such an assumption is not so far-fetched from the reality as many scholarships in the natural sciences [the quantitative] have had long tradition with co-authorship (in terms of joint publication) as opposed to scholarships in the social sciences. Hence, the action co-author potentially yields the highest payoff for player 2 but not for player 1 . The rationality concept then assumes player 1 , who is the player moving at node 3, will play co-exist, for this action yields the best payoff for him.

${ }^{9}$ This solution concept is also known as forward induction in the game theory literature. See Andreas Perea (2010) for more interesting read on forward (versus backward) induction reasoning in game theory.

${ }^{10}$ Players can rank all outcomes; objective preference over outcomes can be established. 
The question then arises as to why player 2, despite knowing (in line with the rationality concept) that player 1 will prevent her from realizing her best possible payoff at node 3, still chooses collaborate. To answer this question, one needs to look at the possible payoffs at node 4 . Fuse seems to possibly yield the worst payoff in the game. The expected lower value of $\Omega$ and potentially very high value of $C$ might render the final payoff for upskill inferior than those potential payoffs at node 3. Furthermore, player 2 rationally believes that player 1 would have been better off resisting to play the game in the first place had he known the game would have ended at node 4.

Therefore, the game's equilibrium (solution)is reached at node 3 with the strategy change - collaborate - co-exist. This indeed represents the current reality of the real-world situation. It is imperative to further defines co-author and co-exist as their use in this article may be different from their conventional use or existing common understanding.

Co-author refers to collaboration between qualitative and quantitative scholars in which both make conscious effort at learning and understanding each other's technical knowledge to a reasonable degree. By reasonable degree means both authors can describe and justify the use of approaches and methods by one another. ${ }^{11}$ Co-exist refers to collaboration in which authors are concerned only with their own expertise without making conscious effort at learning and understanding one another's expertise to a reasonable degree. In a nutshell, while co-author assumes new learning to have taken place as a result of intense intellectual exchange between qualitative and quantitative scholarship, co-exist assumes no (minimal if any) learning has taken place as a result of both qualitative and quantitative scholarship maintaining their respective expertise or technical knowledge.

\footnotetext{
${ }^{11}$ This collaborative endeavor is not necessarily easy. Insofar as it involves interdisciplinary endeavor, there needs to be a thorough framework that is comprised of three key stages namely conceptual design, technical design and integration (See Tobi \& Kampen, 2018).
} 
Thus it is not difficult to identify co-exist in the current situation. Authors jointly write an article; each (assuming authors represent the qualitative and the quantitative scholarship) takes care of his own part or substantive portion of the article. The idea is to produce a joint article without necessarily putting deliberate effort at learning about one other's expertise. Perhaps there is some discussion but such discussion is merely to better coordinate the joint publication. No substantial learning is to take place as no change in behavior is expected of authors.

Scholars are not to be blamed as the need for joint articles has become necessary these days. In Malaysia's IR academic, joint articles have grown in numbers over the years, although some $90 \%$ of these joint articles are still intra-field (within the IR field) rather than inter-field (between or among different fields). And because there are very limited number of scholars with quantitative inclination, such intra-field has mainly been qualitative on different subject areas. Even then many of these intra-field joint articles are hardly of co-author attribute as authors remain compartmentalized within their respective subject matters.

The situation gets even more daunting when one speaks of upskilling and forming a hybrid (fusion) within the qualitative scholarship. From the model, both upskill and fuse are the two least preferred options for the qualitative scholarship. Again, this is not surprising given the cost involved in choosing these two options. Upskill requires the qualitative scholars to undertake learning new sets of skills [quantitative]. Depending upon the career level of the qualitative scholars, learning these new skills may incur many outlays. More senior ones may find it difficult to find the time and courage (energy) to subscribe for specific courses regardless of their intensity. There are also emotional and psychological cost namely loosing face (failure to acquire the skills can lead to personal embarrassment) or peer pressure (the inability to grasp new concepts can lead to the inability to catch up with the rest who will in turn put more pressure on one's speed and performance). 
Fuse presents the biggest dilemma to both the qualitative and the quantitative scholarship. Here fuse entails an emergence of an entirely new breed of scholars who can be regarded as the offsprings of the qualitative and the quantitative scholarship bonded together. The result is a new scholarship that displays eloquence and competence in both qualitative and quantitative tradition. Both their ontological as well as epistemological attributes are different from their parents hence they view the world in an entirely different perspectives, of course depending upon their personal and professional motivations.

Here is where the paradox is. Although by virtue of its ideal character, fuse should be a welcome product hence yields the highest payoff among all the other actions. Nonetheless, as reflected in the utility function of both players, maintaining epistemology is sentimental to both scholarships. This model assumes the qualitative to suffer costlier costs than would be the quantitative. Although, generally, both scholarships do not benefit from such fuse option. This analysis also shares the view that fuse is not a practical option as there is a common interest to maintain intellectual varieties and traditions to arrive at multi-perspective worldview. A fusion or a hybrid scholarship may sound chic or fashionable but may lack strong and distinctive intellectual roots.

Nonetheless, the new disruptive era we are currently living in is obliging us to adapt to transformative way of doing things. For one thing, itis about surviving the promotional exercise in the academia that is of an issue here. Qualitative academics in Malaysia (and in many other Southeast Asian countries, even the world over) have been pressured to collaborate with their quantitative counterparts (especially those with data and numerical skill) in order to get their work published in highly reputable journal. More and more of these highly sought-after journals are explicit in their demand and preference for quantitative rather than qualitative submissions. As publishing in these high-ranking journals count significantly toward promotion, joint and collaborative publications seem to be the most pragmatic solution. Though, in some 
desperate cases, qualitative scholars' role in such joint publications are reduced to editorial role- copyediting the grammar and structures.

The preceding paragraph is just a small part of a much bigger picture that concerns this article. It pertains to the epistemological issue, which largely determines the survival of, not scholars per se, but more importantly the approach's existentiality. Imagine the Arab Spring phenomenon. Many would agree that it was a phenomenon whose fate was defined by the virtual reality. The communication technology fundamentally drove and shaped the phenomenon at the expense of control by the states' authority and political forces.

Of course the details of the Arab Spring phenomenon is beyond the scope of this article. However, what interests the article the most is the fact that the phenomenon produced obscene amount of data- virtual data that accumulated over the evolving years of the Arab Spring on social media and the Internet. One then asks the question, "what do IR scholars [qualitative] make of these data?" It is almost unthinkable that the qualitative scholarship will be able to succinctly account for all these data purely in an interpretevist way. Even if one were to employ a casestudy approach, a good use of quantitative methods is necessary if not obligatory to ensure that the case study (single case or multiple cases) captures the real essence of the case(s) in question. A sophisticated methodological software like phyton maybe useful to extract the massive amount of virtual chat sessions, postings, images, videos and narratives on various social media and the Internet platforms. Count in those digital content on millions of mobile devices, one will be immediately overwhelmed by the rich and extensive data to be analyzed.

There is no denying that the Arab Spring phenomenon may not be of prime interest to IR scholars in Malaysia or the region generally. Nonetheless, there are simply many similar phenomena that produce rich digital data. The fateful May 9, 2018 in the Malaysian politics is one of these phenomena. IR scholars interested in the role of domestic polities e.g., domestic institutional reforms; partisan political leadership, may be 
forced to gather the tremendous amount of digital data and content of events before, during and immediately after the elections. Although the IR scholars may focus on the macro aspect of things, such macro analysis must adequately account the essential of the micro aspects which are derived from those zillions of digital data on the events.

The trend of political leaders, domestic or international, using social media applications e.g., facebook, twitter and instagram demonstrates how, in recent years, political leadership hence policymaking have been occurring in the virtual space. These technology platforms allow for observations- once not categorically possible in the old analog dayson leaders' and policymakers' motives and preferences conveniently possible. Messages and postings on these social media applications open up the private side of these leaders and policymakers, especially when one can access to their personal accounts.

Hence, for game theorists, Trump's tweets on his personal twitter account are as equally, if not more, valuable as his official statements issued by the institutional sources. Contradictions between personal and official statements that many mull over are indeed some of the best indicators of what to ensue in reality. Many times, these personal tweets or instagram images precede the long-awaited official statement that go through so many risk-evaluation procedures. Ironically, public perceptions are formed around these personally released cues that then transform themselves into national discourse. Putting aside the fake-truth debate, it would be ignorant not to take these digital data and incorporate them into one's research analysis.

\section{Conclusion}

It is the effect of the big data phenomenon. No research on any subject matter can escape this influx of data for analysis. It is in this context this article concludes with a propositional game theoretic model, the paradigm-shift model, that tries to improve on the current status quo model. Still maintaining the essential features of the status 
quo game model, the proposed model aims at modifying some of the perimeters of the game to result in much better equilibria available for both the qualitative and the quantitative scholarship.

The proposed game theoretic model, the Qualy-Quanty Game: The Paradigm-Shift Model, is presented in figure 2 below:

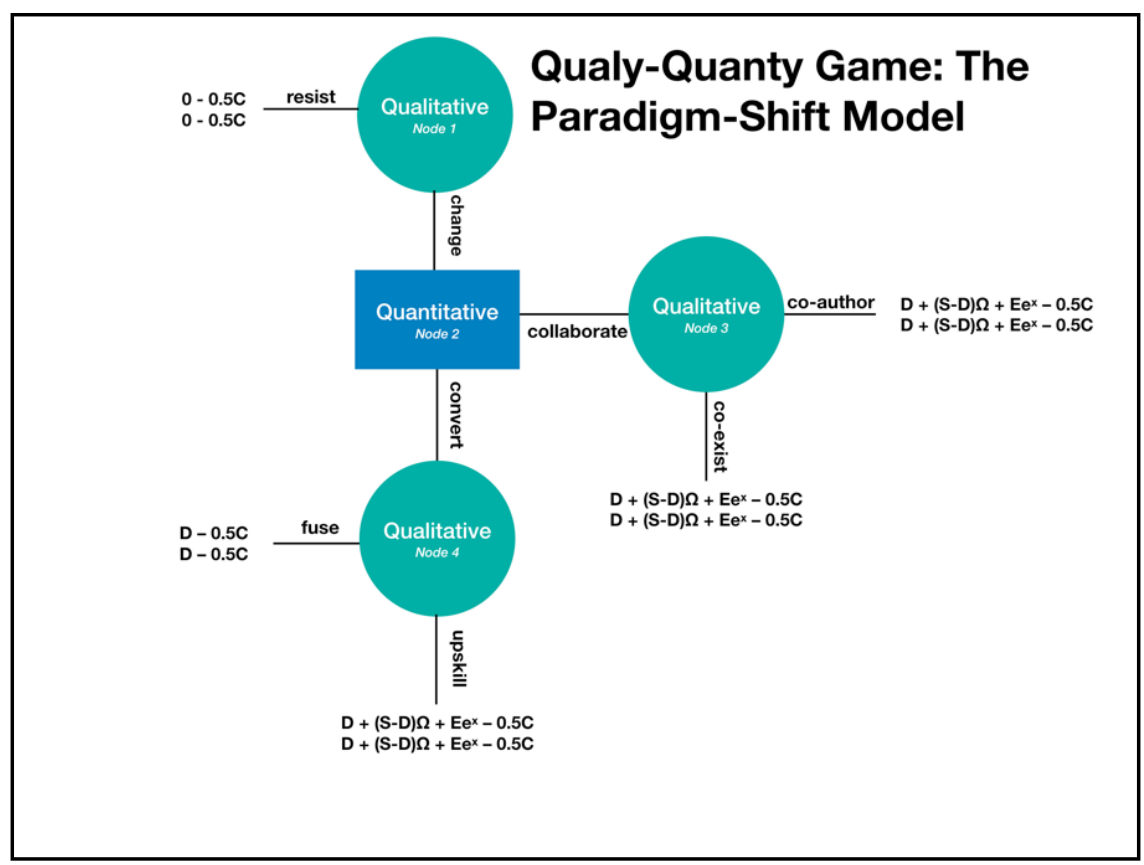

Figure 2. The Paradigm-Shift Model

Source: Author's Compilation

From the satus quo model, we saw there exists a unique equilibrium or solution to the game. The co-exist strategy becomes the best response to the collaborate strategy player 2 plays. Neither player sees the utility of playing at node 4 despite the potential benefits of upskilling among the qualitative scholarship as discussed in the preceding paragraphs.

Further analysis of the status quo model also clearly reveals that while co-exist is being preferred, its utility is not necessarily greater than co-author. What this means is that such co-exist equilibrium is not stable as a small change in the payoffs can alter altogether the game's outcome. Qualitatively, one can also argue that opting for co-exist is not a sustainable strategy moving forward for the qualitative scholarship. 
The payoff situation in the status quo game model can also be attributed to the rather passive role of the quantitative scholarship. The status quo model does not make explicit assumptions on the nature of player 2. Imagine a mathematical scholar who is seeking for an IR scholar to study the probability of the South China Sea territorial claims producing a catastrophic armed conflict. The theoretically sophisticated IR scholar is likely to brief the number-crunching mathematician on the long-established threat narrative (assuming the dominant realist paradigm in IR). The former will repeatedly inform the latter that his pool of experts' opinion and field- observation data can convincingly confirm how, if the situation remains unchecked, physical conflict is highly likely.

Then the dull but curious mathematician asks a basic yet fundamental question, "do things remain unchanged?" To this, the IR scholar puzzlingly shaking his head while wondering hard what could be the real question instead. Having anticipated such an answer from an expert IR academic, the mathematician began to introduce to the IR scholar the Bayesian probability.If the phenomenon follows a dynamic pattern, the probabilities must also dynamically change. States just like people learn and update themselves with newer information to make sense of a phenomenon. Knowledge about leader's ever-changing policy environment is crucial in determining the equilibrium of the conflict in question. Yesterday one might predict a war was ripe; today a peace dividend presents itself on the table. A sound scholarship must not fail to identify and do the necessary assessment of such change.

The above anecdotal illustration does not in any way mean to offend the many qualitative IR scholars (even in Malaysia) who are familiar with the Bayesian theorem. What it simply tries to highlight is the fact that small interaction like the one depicted between the IR scholar [qualitative] and the mathematician [quantitative] can result in a significant intellectual transformation. 
The desire for change may be higher among the qualitative scholarship whose existence is being seriously threatened by the big-data phenomenon. However, the quantitative scholarship does not necessarily have to play audience to such a change. The change indicates new opportunities for the quantitative scholarship as there are potentially many new areas of research that can be harnessed. A strategic intellectual partnership between the two scholarships will only guarantee more value-adds to the quantitative scholarship. Hence, the cost for such change must not be unique to one party [the qualitative] but must be equally shared by both parties [the qualitative and the quantitative scholarship]. This then leads to the proposed paradigmshift model to infuse the $0.5 \mathrm{C}$ to represent the equally shared cost between the two scholarships.

Using the proposed paradigm-shift model, collaboration and conversion are pursued in partnership. This partnership reflects mutual support and shared risks (in terms of the cost). As a result the sub-game at node 3, for instance, can lead players to prefer co-authorship rather than merely co-existence.

Consistent interaction between and among the qualitative and the quantitative scholarship can pave the way for qualitative scholarship to prefer upskilling themselves. The article discusses earlier how conversion may be a painful experience especially for hard-core senior IR scholars. Nonetheless, as much as peers can be a source of stress and tension, peers can also be a source of strong support. It is at this juncture the paradigm-shift model modifies the quantitative scholarship's attitude toward supportively converting their qualitative counterparts. The outlays [cost] associated with upskilling are being shared- as demonstrated by the $0.5 \mathrm{C}$ in the utility functions of both players. By changing the payoff matrix for upskill, the proposed model effectively changes the game's preferences hence the overall game dynamics.

By modifying the utility function of the quantitative scholarship to reflect more rewarding benefits from co-author and upskill, the 
quantitative scholarship find it more morally responsible to help transform their fellow qualitative counterparts to arrive at better research quality and standards. Over time, with good consistency and positive support, the paradigm-shift game model predicts more qualitative scholars will be determined to initiate change as resist becomes costlier. It is at this point the qualitative scholarship has successfully addressed its quantyphobia!

\section{References}

Aronow, P., \& Samii, C. (2016). Does Regression Produce Representative Estimates of Causal Effects? American Journal of Political Science, 60(1), 250-267.

Bas, M. (2012). Democratic Inefficiency? Regime Type and Suboptimal Choices in International Politics. The Journal of Conflict Resolution, 56(5), 799-824.

Battigalli, P. (1997). On rationalizability in extensive games. Journal of Economic Theory, 74, 40-61.

Bellany, I. (1999). Modelling War. Journal of Peace Research, 36(6), 729-739.

Bennett, P. (1991). Modelling Complex Conflicts: Formalism or Expertise? Review of International Studies, 17(4), 349-364.

Bing, N. (2017). Barisan Nasional and the Chinese Communist Party: A Case Study in China's Party-Based Diplomacy. China Review, 17(1), 53-82.

Buchler, J. (2009). Teaching Quantitative Methodology to the Math Averse. PS: Political Science and Politics, 42(3), 527-530.

De Mesquita, B. B. (2010). The Predictioneer's Game. New York: Random House Trade Paperbacks.

Deutsch, K. W. (1966). Arms Control and the Atlantic Alliance. New York: Wiley. 
Carr, E. H. (1946). The Twenty Years' Crisis 1919 - 1939: An Introduction to the Study of International Relations. London: Macmillan \& Co. Ltd.

Fearon, J. (1995). Rationalist Explanations for War. International Organization, 49(3), 379-414.

Fischer, A. R. H., Tobi, H. \& Ronteltap, A. (2011). When natural met social: a review of collaboration between the natural and social sciences. Interdisciplinary Science Review 36(4), 341-358.

Gilpin, R. (1981). War and Change in World Politics. Cambridge: Cambridge University Press.

Gowa, J., \& Mansfield, E. (1993). Power Politics and International Trade. The American Political Science Review, 87(2), 408-420.

Hammond, P. (2007). Schumpeterian Innovation in Modelling Decicions, Games, and Economic Behavior. History of Economic Ideas, 15(1), 179-195.

Hoff, P., \& Ward, M. (2004). Modeling Dependencies in International Relations Networks. Political Analysis, 12(2), 160-175.

Kim, J., \& Ramirez, P. (2014). Regionalism and Rice Trade in Southeast and Northeast Asia: Making Liberalization Work. Journal of International and Area Studies, 21(2), 83-98.

King, G., \& Zeng, L. (2001). Logistic Regression in Rare Events Data. Political Analysis, 9(2), 137-163.

Korab-Karpowicz, W.J. (2017). Tractatus Politico-Philosophicus: New Directions for the Development of Humankind. New York: Routledge. Kreps, D. M., \& Wilson, R. (1982). Sequential equilibria. Econometrica $50,863-894$.

Krippendorff, E. (1987). The Dominance of American Approaches in International Relations. Journal of International Studies, 16(2), 207-214.

Kristóf, T. (2006). Is it possible to make scientific forecasts in social sciences? Futures 38, 561-574. 
Mares, D. (1988). Middle Powers under Regional Hegemony: To Challenge or Acquiesce in Hegemonic Enforcement. International Studies Quarterly, 32(4), 453-471.

Mearsheimer, J. J. (1994). The False Promise of International Institutions. International Security, 19(3), 5-49.

Miller, J. G. (1978). Living Systems. United States of America: McGrawHill.

Moorthy, R., \& Benny, G. (2012). Is an "ASEAN Community" Achievable? Asian Survey, 52(6), 1043-1066.

Moul, W. (1982). Coloring by Numbers: Comments on a Quantitative Study of Quantitative Studies of International Politics. Review of International Studies, 8(2), 129-133.

Nicholson, M. (1989). Formal Theories in International Relations.

Cambridge: Cambridge University Press.

Onwuegbuzie, A. J. \& Leech, N. L. (2005). Taking the "Q" out of research: teaching research methodology courses without the divide between quantitative and qualitative paradigms. Qual. Quant. 39(3), 267-296.

Perea, A. (2010). Backward Induction versus Forward Induction Reasoning. Games, 1, 168-188.

Putnam, R. (1988). Diplomacy and Domestic Politics: The Logic of TwoLevel Games. International Organization, 42, 427-460.

Rathbun, B. (2012). Politics and Paradigm Preferences: The Implicit Ideology of International Relations Scholars. International Studies Quarterly, 56(3), 607-622.

Richardson, L. (1960). Arms and Insecurity. Pittsburgh, Pa.: Boxwood Press.

Schweller, R. (1997). New Realist Research on Alliances: Refining, Not Refuting, Waltz's Balancing Proposition. The American Political Science Review, 91(4), 927-930. 
Sovacool, B., \& Vivoda, V. (2012). A Comparison of Chinese, Indian, and Japanese Perceptions of Energy Security. Asian Survey, 52(5), 949-969.

Tadelis, S. (2013). Game Theory: An Introduction. New Jersey: Princeton University Press.

Tobi, H. \& Kampen, J. K. (2018). Research design: the methodology for interdisciplinary research framework. Qual. Quant. 52, 1209-1225. Vasquez, J. (1987). The Steps to War: Toward a Scientific Explanation of Correlates of War Findings. World Politics, 40(1), 108-145.

Wayman, F. W. \& Diehl, P. F. (1994). Recontructing Realpolitik. Ann Arbor: The University of Michigan Press.

Wendt, A. (2015). Quantum Mind and Social Science. Cambridge: Cambridge University Press. 